\title{
Analysis of the regional difference in the number of multi-drug prescriptions and its predictors in Japan, 2015-2018
}

Tasuku Okui ${ }^{*}$ (D) and Jinsang Park ${ }^{2}$

\begin{abstract}
Objective: Polypharmacy and multi-drug prescription are major public health problems in Japan, but only a few studies have investigated the regional differences. By revealing regional differences in the multi-drug prescriptions, we can infer regions with high rates of multimorbidity or inappropriate prescribing. This study revealed regional differences in multi-drug prescriptions (the number of simultaneous prescriptions of seven or more internal medicines) and investigated the factors affecting the difference using the National Database of Health Insurance Claims and Specific Health Checkups of Japan data.

Results: The standardized claim ratio (SCR) of the number of multi-drug prescriptions, which corrected the difference in sex and age distribution of prefectures, varied depending on prefectures. A panel data analysis investigating the association between the SCR and explanatory variables (Medical institutions, socioeconomic factors, and physical characteristics of people in prefectures) revealed that the number of public assistance recipients per 1,000 persons was positively and significantly associated with the SCR (Standardized partial regression coefficient $=0.244$, $p$-value $=0.038$ ). In conclusion, regional differences in the number of the multi-drug prescriptions were revealed in Japan, suggesting that public assistance recipients tend to experience multi-drug prescriptions.
\end{abstract}

Keywords: Japan, Prescriptions, Polypharmacy, Public assistance, Database

\section{Introduction}

Polypharmacy is a significant public health issue in many countries [1], including Japan [2]. The age-standardized prevalence rate of polypharmacy (use of five or more oral prescription medications per month) increased from 85.2 to 93.8 per 1,000 persons per month from 2010 to 2016 [2]. Furthermore, the prevalence rate in the population aged 65-79 years is approximately 160 per 1000 people, and the prevalence rate in the population $\geq 80$ years is approximately 300 per 1000 people [2]. The prevalence of the use of five or more drugs in the elderly ranged from

\footnotetext{
*Correspondence: task10300@gmail.com

${ }^{1}$ Medical Information Center, Kyushu University Hospital, Maidashi 3-1-1

Higashi-ku, Fukuoka City, Fukuoka Prefecture 812-8582, Japan

Full list of author information is available at the end of the article
}

26.3\% to $39.9 \%$ in European countries [3] and $36.8 \%$ in the United States [4]. Therefore, the prevalence of polypharmacy in Japan is lower than in the United States, but not particularly lower than in European countries. Polypharmacy can lead to some adverse effects, which tend to occur more frequently as the number of drugs taken increases [5]. The number of prescribed drugs increases with age, and elderly persons particularly need to be given attention in terms of polypharmacy [6].

In order to prevent polypharmacy, some medical fee revisions have been conducted in Japan. Hospitals demand medical fees to the Healthcare bill check and payment organization in the Japanese health insurance system, and prescription fees that the hospital obtains are reduced when seven or more types of internal medicines are prescribed simultaneously to a patient [7]. In addition,

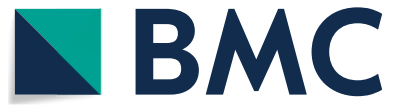

(c) The Author(s) 2021. Open Access This article is licensed under a Creative Commons Attribution 4.0 International License, which permits use, sharing, adaptation, distribution and reproduction in any medium or format, as long as you give appropriate credit to the original author(s) and the source, provide a link to the Creative Commons licence, and indicate if changes were made. The images or other third party material in this article are included in the article's Creative Commons licence, unless indicated otherwise in a credit line to the material. If material is not included in the article's Creative Commons licence and your intended use is not permitted by statutory regulation or exceeds the permitted use, you will need to obtain permission directly from the copyright holder. To view a copy of this licence, visit http://creativecommons.org/licenses/by/4.0/. The Creative Commons Public Domain Dedication waiver (http://creativeco mmons.org/publicdomain/zero/1.0/) applies to the data made available in this article, unless otherwise stated in a credit line to the data. 
the reduction of prescription fees are applied when three or more types of the same kind of psychotropic drugs (one of hypnotics, antidepressants, anxiolytics, and antipsychotics) are prescribed simultaneously [7]. It is important to assess the current status of the multi-drug prescriptions and factors associated with multi-drug prescriptions in Japan using nationally representative data. In other countries, low socioeconomic status as well as multimorbidity are risk factors for polypharmacy [8-11]. In Japan, multimorbidity is a determinant of polypharmacy $[12,13]$, while only a few studies have examined an association between low socioeconomic characteristics and polypharmacy. National Database of Health Insurance Claims and Specific Health Checkups of Japan (NDB) is a database owned by the Ministry of Health, Labour, and Welfare in Japan [14], and it collects most of claims data in all of Japan under a law. The database contains valuable data for revealing trends of prescriptions, diseases, and medical practices in Japan, and it has been used in previous studies. A part of NDB data is publicly available now as NDB Open data, and studies using them have been conducted recently [15-17]. NDB Open data contains prescription data by prefecture, and it will be useful for revealing regional differences in prescription trends [18]. On the other hand, studies revealing regional differences in multi-drug prescriptions are few in Japan. By revealing regional differences in the multi-drug prescriptions, we could infer regions where the proportion of multimorbidity patients is large or inappropriate prescriptions are conducted. NDB data have been used by the Ministry of Health, Labour, and Welfare for revealing regional differences in proportions of multi-drug prescriptions among all the prescriptions [19]. However, only out-of-prescriptions data gathered from pharmacies have been used [19], and regional differences taking into account in-hospital prescriptions have not been revealed. In addition, we need to take into account the population for each prefecture to compare the number of multidrug prescriptions among prefectures. Moreover, a study investigating the factors affecting the regional difference has not been conducted in Japan, and the reason for the regional difference is unknown.

In this study, we revealed regional differences in the number of multi-drug prescriptions in Japan and investigated the factorsaffecting the difference.

\section{Main text}

\section{Materials and methods}

In Japan, prescription fees that a medical institution obtains are reduced when seven or more types of internal medicines are simultaneously prescribed to a patient (exceptions are in case of emergency and short administration periods), and the number of multi-drug prescriptions can be determined from claims data. Therefore, medical practice codes of simultaneous prescription of seven or more types of internal medicines were used as an indicator for multi-drug prescriptions (Medical practice code in Japan: 120002610 and 120002710). The number of claims by year, age group, sex, and the number of claims by year for each prefecture in Japan were obtained from the NDB Open data [20]. In addition, we obtained population data by year, age group, and sex from the Basic Resident Register data in Japan [21].

Variables related to medical institutions, socioeconomic factors, and physical characteristics of people in prefectures were used as factors for investigating the association with the number of the simultaneous prescriptions of seven or more types of internal medicines. The variable used and the data source are shown in Additional file 1: Table S1 [20, 22, 23]. The specific health checkups are conducted every year for insured persons and their dependents aged 40-74 years [24]. Data from 2015 to 2018 are publicly available for multi-drug prescriptions, but all the data for each prefecture could only be obtained from 2015 to 2017 . Therefore, data from 2015 to 2017 were used for the regression analysis.

For the statistical analysis, we calculated the number of claims for the multi-drug prescription per capita in Japan by sex and age group, and calculated the expected number of the claims for each prefecture taking into account age group and sex-specific population for each prefecture. Then, we calculated the standardized claim ratio (SCR) from the actual number of claims and the expected number of claims as is conducted in previous studies $[25,26]$. The mean of SCR is set to be 100 for each year. In addition, a linear mixed-effects model was used in panel data analysis to determine if there is an association between the SCR and the explanatory variables, and information on prefecture was used as a random effect. The outcome (SCR) and the explanatory variables were standardized, and standardized partial regression coefficient (SPRC) and 95\% confidence intervals were calculated. A statistically significant difference was judged based on a p-value $<0.05$, and two-sided statistical tests were conducted. All statistical analyses were conducted using R 3.6.3 (https://www.r-project.org/). This study does not require the approval of an institutional review committee, as it analyzed publicly available government statistics. Data did not include individual information of patients.

\section{Results}

Table 1 shows the number of the multi-drug prescription per 1000 persons by age group, sex, and year. The number of claims per 1000 persons increased with age, 


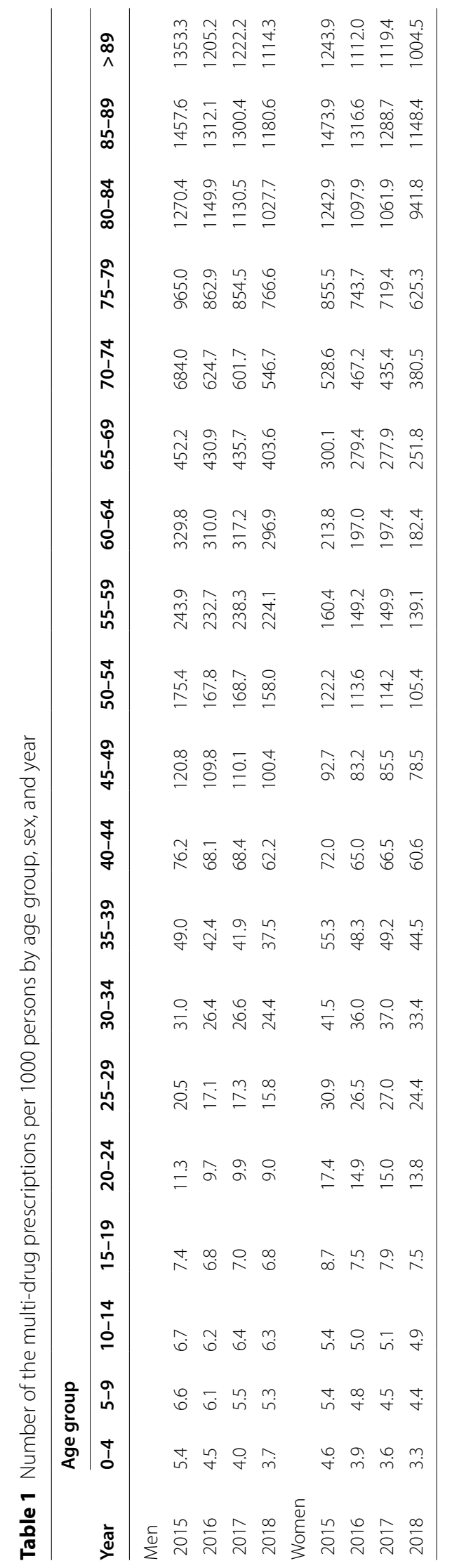


and the number tended to be larger for men than that for women in the middle ages.

Table 2 shows the number of the multi-drug prescription per 1,000 persons and SCR by year and prefecture. The SCR varied depending on prefectures, and the yearly fluctuation of the value was small. The SCR for Nagasaki was the largest every year, and those for Hiroshima and Saga were also large compared with the other prefectures. In contrast, the SCR for Toyama was the smallest every year, and those for Wakayama and Fukui were also relatively small.

The Additional file 1: Table S2 shows the median (Q1Q3) of the explanatory variables used in the linear mixedeffects model.

Table 3 shows the results of the linear mixed-effects model. The absolute value of SPRC indicates the degree of association between the explanatory variable and the outcome, and the larger the SPRC, the stronger is the association. The linear mixed-effects model assumes that the outcome variables follow a normal distribution, thereby confirming that the SCR distribution does not deviate significantly from the normal distribution.

As a result, the number of public assistance recipients per 1000 persons was positively associated with the SCR $(\mathrm{SPRC}=0.244$, $\mathrm{p}$-value $=0.038)$, and the absolute value of the SPRC was also the largest among the explanatory variables. On the other hand, the physical characteristics were not associated with the outcome.

\section{Discussion}

We showed regional differences in multi-drug prescriptions in Japan and identified a factor associated with the difference. The number of multi-drug prescriptions in a prefecture was associated with the number of recipients of public assistance in the prefecture. Here we briefly discuss the possible reasons for this association.

Persons with low income have been shown to be related to multimorbidity. Multimorbidity is closely related to polypharmacy [27, 28], and is considered to be a cause of multi-drug prescription. There are many studies that show the association between multimorbidity and low socioeconomic status $[29,30]$. Low socioeconomic status is associated with several causes of morbidity in Japan, such as obesity, hypertension, diabetes complications, and psychological distress [31-34]. It is also related to health behaviors, such as smoking and heavy alcohol drinking [35]. Moreover, low socioeconomic status leads to lower utilization of medical care [36, 37], and there is a possibility that delay of early treatment and early detection of diseases can lead to multimorbidity.

In addition, it is considered that patients with multimorbidity or psychiatric diseases tend to become recipients of public assistance because these patients have difficulties in working $[38,39]$. The proportion of lifestyle-related diseases are known to be higher in recipients of public assistance compared with the general population [40]. In addition, the prevalence of patients with a psychiatric disease is higher in recipients of public assistance [41], and psychiatric diseases and lifestylerelated diseases, such as metabolic syndromes, have been reported to be closely related [42]. Besides, it is known that a certain number of recipients of public assistance frequently consult a medical institution [43], possibly because hospital visits are free of charge for recipients of public assistance. These frequent visits to a hospital might be somehow related to the multi-drug prescriptions.

On the other hand, physical characteristics related to lifestyle-related diseases were not associated with the outcome. It is known that obesity or other lifestylerelated diseases are associated with polypharmacy [44-46]. Participation in specific health checkups is not mandatory in Japan [47]; thus, there is a possibility that people with low health status tended not to participate in the checkups. In addition, uninsured persons do not participate in the checkups. Therefore, there is a possibility that the participation rate per capita varied depending on prefectures, which might have affected the results regarding the physical characteristics.

This study indicated a possibility that public assistance recipients tend to experience multi-drug prescriptions and fall into polypharmacy. It is considered that multimorbidity patients or psychiatric patients tend to become recipients of public assistance. However, for some public assistance recipients, there are cases of excessive multidrug prescriptions. Therefore, it is necessary for medical practitioners and social workers to recheck the number of medicines taken by public assistance recipients and their consultation behaviors to medical institutions. In addition, putting restrictions on frequent visits to medical institutions might be needed for some recipients of public assistance, in order to prevent unnecessary multidrug prescriptions.

\section{Limitations}

There are some limitations to this study. First, the classification of claims data by the prefectures was conducted based on the place of medical institutions, and some differences between a prefecture of medical institutions where multi-drug prescriptions were conducted and a prefecture where a patient with multi-drug prescriptions lives may have existed. Secondly, this is an ecological study, and there was a possibility that the association would not be evident upon analysis of individual data. A further study investigating an association between the recipient of public assistance and multidrug prescriptions using individual data is needed for 
Table 2 Number of the multi-drug prescriptions per 1000 persons and the SCR by year and prefecture

\begin{tabular}{|c|c|c|c|c|c|c|c|c|}
\hline \multirow[b]{2}{*}{ Prefecture } & \multicolumn{4}{|c|}{ Number of the multi-drug prescriptions per 1,000 persons } & \multicolumn{4}{|l|}{$\mathrm{SCR}$} \\
\hline & 2015 & 2016 & 2017 & 2018 & 2015 & 2016 & 2017 & 2018 \\
\hline Hokkaido & 373.3 & 341.7 & 343.3 & 324.0 & 126.1 & 125.3 & 124.8 & 127.9 \\
\hline Aomori & 363.1 & 338.8 & 342.7 & 320.4 & 118.0 & 119.6 & 119.7 & 121.4 \\
\hline Iwate & 313.7 & 291.0 & 296.0 & 272.8 & 98.4 & 99.5 & 100.7 & 101.0 \\
\hline Miyagi & 312.3 & 285.9 & 286.7 & 266.9 & 115.6 & 115.3 & 114.7 & 116.0 \\
\hline Akita & 413.9 & 376.0 & 373.9 & 349.0 & 118.7 & 117.4 & 115.9 & 117.8 \\
\hline Yamagata & 290.0 & 271.4 & 275.1 & 256.6 & 89.0 & 91.1 & 92.1 & 93.9 \\
\hline Fukushima & 359.9 & 327.4 & 326.6 & 294.8 & 119.9 & 119.3 & 118.3 & 116.2 \\
\hline Ibaraki & 278.3 & 258.6 & 259.1 & 240.9 & 102.8 & 103.5 & 102.8 & 103.6 \\
\hline Tochigi & 271.2 & 246.2 & 248.6 & 229.8 & 101.1 & 99.7 & 99.9 & 100.2 \\
\hline Gunma & 264.3 & 242.9 & 245.0 & 222.1 & 94.5 & 94.5 & 94.6 & 93.1 \\
\hline Saitama & 221.3 & 206.4 & 209.3 & 195.3 & 89.8 & 90.4 & 90.4 & 91.1 \\
\hline Chiba & 203.9 & 191.5 & 194.8 & 178.9 & 79.8 & 81.0 & 81.5 & 81.0 \\
\hline Tokyo & 258.6 & 237.3 & 235.5 & 214.7 & 107.8 & 108.3 & 107.3 & 107.0 \\
\hline Kanagawa & 208.0 & 194.1 & 197.0 & 184.0 & 84.4 & 85.3 & 85.6 & 86.6 \\
\hline Niigata & 256.6 & 236.4 & 237.0 & 219.2 & 82.6 & 83.0 & 82.8 & 83.5 \\
\hline Toyama & 232.8 & 213.9 & 213.4 & 195.9 & 76.5 & 76.7 & 76.1 & 76.2 \\
\hline Ishikawa & 286.2 & 263.6 & 263.8 & 239.0 & 102.0 & 102.3 & 101.7 & 100.3 \\
\hline Fukui & 234.5 & 214.2 & 215.0 & 198.7 & 80.0 & 79.8 & 79.9 & 80.5 \\
\hline Yamanashi & 306.0 & 277.8 & 277.2 & 250.4 & 104.2 & 103.0 & 102.0 & 100.1 \\
\hline Nagano & 280.0 & 252.0 & 255.2 & 232.8 & 90.6 & 89.2 & 90.1 & 89.7 \\
\hline Gifu & 248.3 & 223.8 & 228.8 & 209.0 & 87.6 & 86.0 & 87.2 & 86.6 \\
\hline Shizuoka & 232.8 & 213.3 & 214.8 & 197.5 & 82.7 & 82.3 & 82.3 & 82.2 \\
\hline Aichi & 208.1 & 192.5 & 196.0 & 178.9 & 85.5 & 85.9 & 86.8 & 86.0 \\
\hline Mie & 228.8 & 206.1 & 211.7 & 192.0 & 80.8 & 79.2 & 80.9 & 79.7 \\
\hline Shiga & 226.6 & 209.3 & 211.2 & 189.9 & 90.2 & 90.6 & 90.6 & 88.5 \\
\hline Kyoto & 231.4 & 214.3 & 216.5 & 198.7 & 83.5 & 84.0 & 84.2 & 84.0 \\
\hline Osaka & 259.3 & 241.4 & 245.4 & 221.9 & 100.4 & 101.0 & 101.6 & 99.8 \\
\hline Hyogo & 259.9 & 238.4 & 240.1 & 220.4 & 96.1 & 95.6 & 95.3 & 95.0 \\
\hline Nara & 243.3 & 229.1 & 234.4 & 219.6 & 85.6 & 87.1 & 88.0 & 89.2 \\
\hline Wakayama & 246.8 & 224.2 & 227.1 & 206.0 & 79.6 & 78.7 & 79.1 & 78.2 \\
\hline Tottori & 293.5 & 271.2 & 279.2 & 253.5 & 94.8 & 96.0 & 98.6 & 97.7 \\
\hline Shimane & 369.6 & 333.8 & 341.2 & 320.7 & 110.1 & 109.3 & 111.6 & 115.3 \\
\hline Okayama & 338.6 & 304.0 & 300.1 & 276.3 & 116.5 & 114.2 & 112.2 & 112.8 \\
\hline Hiroshima & 371.8 & 336.4 & 333.8 & 298.8 & 133.1 & 131.2 & 129.4 & 126.3 \\
\hline Yamaguchi & 340.1 & 308.2 & 312.3 & 282.0 & 105.7 & 104.5 & 105.3 & 103.8 \\
\hline Tokushima & 281.6 & 254.3 & 262.2 & 241.0 & 89.5 & 88.2 & 90.7 & 90.8 \\
\hline Kagawa & 336.5 & 311.5 & 319.5 & 305.2 & 112.8 & 114.2 & 116.6 & 121.6 \\
\hline Ehime & 241.1 & 223.8 & 230.0 & 214.2 & 77.7 & 78.7 & 80.5 & 81.8 \\
\hline Kochi & 377.5 & 345.1 & 347.1 & 322.6 & 113.1 & 113.0 & 113.1 & 114.9 \\
\hline Fukuoka & 317.7 & 291.8 & 293.8 & 268.6 & 120.2 & 120.3 & 120.5 & 120.2 \\
\hline Saga & 388.3 & 353.6 & 353.4 & 325.8 & 134.0 & 133.2 & 132.7 & 133.7 \\
\hline Nagasaki & 438.6 & 399.3 & 392.6 & 351.3 & 142.6 & 141.5 & 138.3 & 134.9 \\
\hline Kumamoto & 357.4 & 324.7 & 326.2 & 299.0 & 118.1 & 117.4 & 117.6 & 117.9 \\
\hline Oita & 362.6 & 332.4 & 335.1 & 310.1 & 116.8 & 116.9 & 117.2 & 118.3 \\
\hline Miyazaki & 331.9 & 306.5 & 312.0 & 290.0 & 108.7 & 109.4 & 110.7 & 112.3 \\
\hline Kagoshima & 340.0 & 303.1 & 301.8 & 280.8 & 109.0 & 106.4 & 105.8 & 107.8 \\
\hline Okinawa & 222.4 & 210.5 & 213.9 & 199.6 & 100.3 & 103.2 & 103.9 & 105.1 \\
\hline
\end{tabular}

SCR standardized claim ratio 
Table 3 The results of linear mixed effects model

\begin{tabular}{|c|c|c|}
\hline Variable & SPRC $(95 \% \mathrm{CI})$ & p-value \\
\hline \multicolumn{3}{|l|}{ Medical institutions } \\
\hline Number of hospitals per 100,000 persons & $0.190(-0.095,0.477)$ & 0.216 \\
\hline Number of medical clinics per 100,000 persons & $-0.075(-0.294,0.144)$ & 0.522 \\
\hline Number of pharmacies per 100,000 persons & $0.124(-0.024,0.285)$ & 0.106 \\
\hline \multicolumn{3}{|l|}{ Socioeconomic factors } \\
\hline Population density (person per hectare) & $0.060(-0.268,0.389)$ & 0.733 \\
\hline Proportion of non-Japanese persons & $0.011(-0.189,0.203)$ & 0.914 \\
\hline Number of public assistance recipients per 1000 persons & $0.244(0.027,0.461)$ & 0.038 \\
\hline Taxable income per capita (unit: 1000 yen) & $-0.045(-0.318,0.222)$ & 0.752 \\
\hline Financial capability index & $-0.098(-0.343,0.159)$ & 0.458 \\
\hline \multicolumn{3}{|l|}{ Physical characteristics } \\
\hline Proportion of persons whose HbA1c (NGSP) $\geq 6.5$ (\%) & $0.018(-0.037,0.073)$ & 0.546 \\
\hline Proportion of persons whose systolic BP $\geq 140(\mathrm{mmHg})$ & $0.020(-0.062,0.100)$ & 0.640 \\
\hline Proportion of persons whose $\mathrm{BMI} \geq 25\left(\mathrm{~kg} / \mathrm{m}^{2}\right)$ & $0.028(-0.106,0.163)$ & 0.697 \\
\hline Proportion of persons whose triglycerides $\geq 150(\mathrm{mg} / \mathrm{dl})$ & $-0.021(-0.158,0.111)$ & 0.763 \\
\hline Proportion of elderly persons requiring support or nursing care & $0.026(-0.079,0.133)$ & 0.646 \\
\hline
\end{tabular}

$S P R C$ standardized partial regression coefficient, $C l$ confidence intervals, NGSP National Glycohemoglobin Standardization Program, $B P$ blood pressure, $B M I$ body mass index

verification. Thirdly, we could not reveal the types of drugs for the multi-drug prescriptions and the diseases of patients to whom multi-drugs prescriptions were given. By revealing these characteristics, we could better understand the reason for the regional differences. Finally, some unobserved confounding factors might explain the association between the number of the recipients of public assistance and the multi-drug prescriptions. Factors, such as proportion of persons having psychological distress, proportion of patients with chronic diseases, frailty, and educational level need to be taken into account in a future research [48-50]. On the other hand, this study used the NDB data in Japan, and the results of this study represents trends in all of Japan and are generalizable to all Japnanese people.

\section{Abbreviations}

SPRC: Standardized partial regression coefficient; Cl: Confidence intervals; NGSP: National Glycohemoglobin Standardization Program; BP: Blood pressure; BMI: Body mass index; SCR: Standardized claim ratio (SCR); NDB: National Database of Health Insurance Claims and Specific Health Checkups of Japan (NDB.

\section{Supplementary Information}

The online version contains supplementary material available at https://doi. org/10.1186/s13104-021-05787-2.

Additional file 1: Table S1. Variables used in the analysis. Table S2. Median (Q1-Q3) of the explanatory variables used in the linear mixed effects model.

\section{Acknowledgements}

Enago has proofread the manuscript.

\section{Authors' contributions}

Conceptualization: TO, JP. Data curation: TO. Formal analysis: TO. Methodology: TO. Funding acquisition: JP. Writing —original draft:TO. Writing—review and editing: TO, JP. All authors read and approved the final manuscript.

Funding

This research was supported by the JSPS KAKENHI Grant Number $21 \mathrm{~K} 17231$.

\section{Availability of data and materials}

The data used in this study can be obtained from websites of government statistics in Japan (The Survey of population, demographics, and household number based on the basic resident register. [cited 17 July 2021]. Available from: https://www.e-stat.go.jp/stat-search/files?page $=1$ \&toukei $=00200241 \&$ tstat=000001039591; e-Stat General counter for government statistics. [cited 17 July 2021]. Available from: https://www.e-stat.go.jp/regional-statistics/ ssdsview; NDB Open data. [cited 17 July 2021]. Available from: https://www. mhlw.go.jp/stf/seisakunitsuite/bunya/0000177182.html..iData of the Report on the Status of the Long-term Care. [cited 19 August 2021]. Available from: https://www.e-stat.go.jp/stat-search/files?page $=1 \&$ toukei $=00450351 \&$ tstat $=$ 000001031648.

\section{Declarations}

\section{Ethics approval and consent to participate}

Not applicable. We analyzed government statistics data that are publicly available. No administrative permissions were required to access the data used in this study.

\section{Consent for publication}

Not applicable.

\section{Competing interests}

The authors have no conflict of interest associated with the material presented in this paper. 


\section{Author details}

${ }^{1}$ Medical Information Center, Kyushu University Hospital, Maidashi 3-1-1 Higashi-ku, Fukuoka City, Fukuoka Prefecture 812-8582, Japan. ${ }^{2}$ Department of Pharmaceutical Sciences, International University of Health and Welfare, Fukuoka, Japan.

Received: 21 July 2021 Accepted: 14 September 2021 Published online: 20 September 2021

\section{References}

1. Masnoon N, Shakib S, Kalisch-Ellett L, Caughey GE. What is polypharmacy? A systematic review of definitions. BMC Geriatr. 2017;17(1):230.

2. Onoue H, Koyama T, Zamami Y, Hagiya H, Tatebe Y, Mikami N, Shinomiya K, Kitamura Y, Hinotsu S, Sendo T, Ouchi Y, Kano MR. Trends in polypharmacy in Japan: A Nationwide Retrospective Study. J Am Geriatr Soc. 2018;66(12):2267-73.

3. Midão L, Giardini A, Menditto E, Kardas P, Costa E. Polypharmacy prevalence among older adults based on the survey of health, ageing and retirement in Europe. Arch Gerontol Geriatr. 2018;78:213-20.

4. Young EH, Pan S, Yap AG, Reveles KR, Bhakta K. Polypharmacy prevalence in older adults seen in United States physician offices from 2009 to 2016. PLOS ONE. 2021:16(8):e0255642.

5. Kojima T, Akishita M, Kameyama Y, Yamaguchi K, Yamamoto H, Eto M, Ouchi Y. Factors associated with prolonged hospital stay in a geriatric ward of a university hospital in Japan. J Am Geriatr Soc. 2012;60(6):1190-1.

6. Mabuchi T, Hosomi K, Yokoyama S, Takada M. Polypharmacy in elderly patients in Japan: analysis of Japanese real-world databases. J Clin Pharm Ther. 2020:45(5):991-6.

7. Ministry of Health, Labour and Welfare. Medical fee revision. [cited 20219 June]. Available from: https://www.mhlw.go.jp/stf/seisakunitsuite/bunya/ 0000106602.html.

8. Assari S, Bazargan M. Race/ethnicity, socioeconomic status, and polypharmacy among older Americans. Pharmacy (Basel). 2019;7(2):41.

9. Slater N, White S, Venables R, Frisher M. Factors associated with polypharmacy in primary care: a cross-sectional analysis of data from The English Longitudinal Study of Ageing (ELSA). BMJ Open. 2018;8(3):e020270.

10. Aggarwal P, Woolford SJ, Patel HP. Multimorbidity and polypharmacy in older people: challenges and opportunities for clinical practice. Geriatrics (Basel). 2020;5(4):85.

11. Castioni J, Marques-Vidal P, Abolhassani N, Vollenweider P, Waeber G. Prevalence and determinants of polypharmacy in Switzerland: data from the CoLaus study. BMC Health Serv Res. 2017;17(1):840.

12. Aoki T, Yamamoto Y, Ikenoue T, Onishi Y, Fukuhara S. multimorbidity patterns in relation to polypharmacy and dosage frequency: a nationwide, cross-sectional study in a Japanese population. Sci Rep. 2018;8(1):3806.

13. Morio K, Maeda I, Yokota I, Niki K, Murata T, Matsumura Y, Uejima E. Risk factors for polypharmacy in elderly patients with cancer pain. Am J Hosp Palliat Care. 2019;36(7):598-602.

14. Nakayama T, Imanaka Y, Okuno Y, Kato G, Kuroda T, Goto R, Tanaka S, Tamura H, Fukuhara S, Fukuma S, Muto M, Yanagita M, Yamamoto Y. BiDAME: Big Data Analysis of Medical Care for the Elderly in Kyoto. Analysis of the evidence-practice gap to facilitate proper medical care for the elderly: investigation, using databases, of utilization measures for National Database of Health Insurance Claims and Specific Health Checkups of Japan (NDB). Environ Health Prev Med. 2017;22(1):51.

15. Katano H, Koga H, Ozeki N, Otabe K, Mizuno M, Tomita M, Muneta T, Sekiya I. Trends in isolated meniscus repair and meniscectomy in Japan, 2011-2016. J Orthop Sci. 2018;23(4):676-81.

16. Itoh H, Saito T, Nojiri S, Hiratsuka Y, Yokoyama K. National burden of the pharmaceutical cost of wet compresses and its cost predictors: nationwide cross-sectional study in Japan. Health Econ Rev. 2019;9(1):20.

17. Nakajima A, Sakai R, Inoue E, Harigai M. Geographic variations in rheumatoid arthritis treatment in Japan: a nationwide retrospective study using the national database of health insurance claims and specific health checkups of Japan. Mod Rheumatol. 2021;15:1-9.

18. Koyama T, Zamami Y, Ohshima A, Teratani Y, Shinomiya K, Kitamura Y. Patterns of CT use in Japan, 2014: a nationwide cross-sectional study. Eur J Radiol. 2017;97:96-100.
19. Ministry of Health, Labour and Welfare of Japan. Distribution of number of types of drugs by dispensing. https://www.mhlw.go.jp/bunya/iryou hoken/database/zenpan/dl/cyouzai_doukou_topics_h30_06.pdf. Accessed 20 May 2021.

20. Ministry of Health, Labour and Welfare of Japan. NDB Open. https://www. mhlw.go.jp/stf/seisakunitsuite/bunya/0000177182.html. Accessed 17 July 2021.

21. Ministry of Internal Affairs and Communications. The Survey of population, demographics, and household number based on the basic resident register. https://www.e-stat.go.jp/stat-search/files?page $=1 \&$ toukei= $00200241 \&$ tstat $=000001039591$. Accessed 17 July 2021.

22. Ministry of Internal Affairs and Communications. e-Stat General counter for government statistics. https://www.e-stat.go.jp/regional-statistics/ ssdsview. Accessed 17 July 2021.

23. Ministry of Health, Labour and Welfare of Japan. The Report on the Status of the Long-term Care. https://www.e-stat.go.jp/stat-search/files? page $=1 \&$ touke $=00450351 \&$ tstat $=000001031648$. Accessed 9 August 2021.

24. Nagakura $Y$, Kato H, Asano S, Jinno Y, Tanei S. The significant association between health examination results and population health: a crosssectional ecological study using a Nation-Wide Health Checkup Database in Japan. Int J Environ Res Public Health. 2021;18(2):836.

25. Murakami G, Muramatsu K, Hayashida K, Fijimori K, Matsuda S. Ecological analysis of factors associated with mortality of cerebral infarction in Japan. Asian Pacific J Dis Manage. 2014;6(3-4):73-6.

26. Taira K, Mori T, Ishimaru M, Iwagami M, Sakata N, Watanabe T, Takahashi $H$, Tamiya N. Regional Inequality in Dental Care Utilization in Japan: An Ecological Study Using the National Database of Health Insurance Claims. The Lancet Regional Health—Western Pacific. 2021.

27. Villén N, Guisado-Clavero M, Fernández-Bertolín S, Troncoso-Mariño A, Foguet-Boreu Q, Amado E, Pons-Vigués M, Roso-Llorach A, Violán C. Multimorbidity patterns, polypharmacy and their association with liver and kidney abnormalities in people over 65 years of age: a longitudinal study. BMC Geriatr. 2020;20(1):206.

28. Nguyen TN, Ngangue P, Haggerty J, Bouhali T, Fortin M. Multimorbidity, polypharmacy and primary prevention in community-dwelling adults in Quebec: a cross-sectional study. Fam Pract. 2019;36(6):706-12.

29. Pathirana TI, Jackson CA. Socioeconomic status and multimorbidity: a systematic review and meta-analysis. Aust N Z J Public Health. 2018;42(2):186-94.

30. Kivimäki M, Batty GD, Pentti J, Shipley MJ, Sipilä PN, Nyberg ST, Suominen SB, Oksanen T, Stenholm S, Virtanen M, Marmot MG, Singh-Manoux A, Brunner EJ, Lindbohm JV, Ferrie JE, Vahtera J. Association between socioeconomic status and the development of mental and physical health conditions in adulthood: a multi-cohort study. Lancet Public Health. 2020;5(3):e140-9.

31. Nakamura T, Nakamura Y, Saitoh S, Okamura T, Yanagita M, Yoshita K, Kita Y, Murakami Y, Yokomichi H, Nishi N, Okuda N, Kadota A, Ohkubo T, Ueshima H, Okayama A, Miura K. Relationship between socioeconomic status and the prevalence of underweight, overweight or obesity in a General Japanese Population: NIPPON DATA2010. J Epidemiol. 2018;28(Suppl 3):S10-6.

32. Fukuda $Y$, Hiyoshi A. Influences of income and employment on psychological distress and depression treatment in Japanese adults. Environ Health Prev Med. 2012;17(1):10-7.

33. Funakoshi M, Azami Y, Matsumoto $H$, Ikota A, Ito K, Okimoto H, Shimizu N, Tsujimura F, Fukuda H, Miyagi C, Osawa S, Osawa R, Miura J. Socioeconomic status and type 2 diabetes complications among young adult patients in Japan. PLoS ONE. 2017;12(4):e0176087.

34. Miyaki K, Song Y, Taneichi S, Tsutsumi A, Hashimoto H, Kawakami N, Takahashi M, Shimazu A, Inoue A, Kurioka S, Shimbo T. Socioeconomic status is significantly associated with dietary salt intakes and blood pressure in Japanese workers (J-HOPE Study). Int J Environ Res Public Health. 2013;10(3):980-93.

35. Fukuda Y, Nakamura K, Takano T. Accumulation of health risk behaviours is associated with lower socioeconomic status and women's urban residence: a multilevel analysis in Japan. BMC Public Health. 2005;27(5):53.

36. Hamada S, Takahashi H, Sakata N, Jeon B, Mori T, lijima K, Yoshie S, Ishizaki T, Tamiya N. Household income relationship with health services utilization and healthcare expenditures in people aged 75 years or older 
in Japan: a population-based study using medical and long-term care insurance claims data. J Epidemiol. 2019;29(10):377-83.

37. Fujita M, Sato Y, Nagashima K, Takahashi S, Hata A. Income related inequality of health care access in Japan: a retrospective cohort study. PLOS ONE. 2016;11(3):e0151690.

38. Sum G, Ishida M, Koh GC, Singh A, Oldenburg B, Lee JT. Implications ofmultimorbidity on healthcare utilisation and work productivity by socioeconomic groups: cross-sectional analyses of Australia and Japan. PLOS ONE. 2020:15(4):e0232281.

39. Lerner D, Adler DA, Rogers WH, Chang H, Lapitsky L, McLaughlin T, Reed J. Work performance of employees with depression: the impact of work stressors. Am J Health Promot. 2010;24(3):205-13.

40. Ministry of Health, Labour and Welfare of Japan. 5th Social Security Council "Support the independence of needy persons and public assistance subcommittee." https://www.mhlw.go.jp/stf/shingi2/0000172506.html. Accessed 17 July 2021.

41. Hirokawa S, Oyama S, Oshima I, Tsunoda A, Soeda M, Murashima S, Kayama M. Cooperation between public and private section in the independence support project of public assistance recipients-discussion about necessary techniques for outreach support of community mental health in the future. 2013;22(4):343-357.

42. Penninx BWJH, Lange SMM. Metabolic syndrome in psychiatric patients: overview, mechanisms, and implications. Dialogues Clin Neurosci. 2018;20(1):63-73.

43. Ministry of Health, Labour and Welfare of Japan. $1^{\text {st }}$ Social Security Council "Support the independence of needy persons and public assistance subcommittee." https://www.mhlw.go.jp/stf/shingi2/0000164409.html. Accessed 17 July 2021.

44. Assari S, Wisseh C, Bazargan M. Obesity and Polypharmacy among African American Older Adults: gender as the moderator andmultimorbidity as the mediator. Int J Environ Res Public Health. 2019;16(12):2181.
45. Dobrică EC, Găman MA, Cozma MA, Bratu OG, Pantea Stoian A, Diaconu CC. Polypharmacy in Type 2 diabetes mellitus: insights from an internal medicine department. Medicina (Kaunas). 2019;55(8):436.

46. Mukete BN, Ferdinand KC. Polypharmacy in older adults with hypertension: a comprehensive review. J Clin Hypertens (Greenwich). 2016;18(1):10-8.

47. Hiratsuka Y, Yokoyama T, Yamada M. Higher participation rate for specific health checkups concerning simultaneous ophthalmic checkups. J Epidemiol. 2021;31(5):315-9.

48. Pappa E, Kontodimopoulos N, Papadopoulos AA, Tountas Y, Niakas D. Prescribed-drug utilization and polypharmacy in a general population in Greece: association with sociodemographic, health needs, health-services utilization, and lifestyle factors. Eur J Clin Pharmacol. 2011;67(2):185-92.

49. Wongpakaran N, Wongpakaran T, Sirirak T, Jenraumjit R, Jiraniramai S, Lerttrakarnnon P. Predictors of polypharmacy among elderly Thais with depressive and anxiety disorders: findings from the DAS study. BMC Geriatr. 2018;18(1):309.

50. Herr M, Sirven N, Grondin H, Pichetti S, Sermet C. Frailty, polypharmacy, and potentially inappropriate medications in old people: findings in a representative sample of the French population. Eur J Clin Pharmacol. 2017;73(9):1165-72.

\section{Publisher's Note}

Springer Nature remains neutral with regard to jurisdictional claims in published maps and institutional affiliations.
Ready to submit your research? Choose BMC and benefit from:

- fast, convenient online submission

- thorough peer review by experienced researchers in your field

- rapid publication on acceptance

- support for research data, including large and complex data types

- gold Open Access which fosters wider collaboration and increased citations

- maximum visibility for your research: over $100 \mathrm{M}$ website views per year

At BMC, research is always in progress.

Learn more biomedcentral.com/submissions 